\title{
Effects of Avocado/Soybean on the Chondrogenesis of Human Adipose-Derived Stem Cells Cultured on Polylactic- Co-Glycolic Acid/Fibrin Hybrid Scaffold
}

\author{
Batool Hashemibeni ${ }^{1}$, Mohammad Mardani ${ }^{1}$, Ali Valiani ${ }^{1}$, Majid Pourentezari2* ${ }^{*}$, Morteza Anvari ${ }^{2,3}$, Maryam Yadegari², \\ Esmat Mangoli ${ }^{3}$
}

${ }^{1}$ Department of Anatomical Sciences and Molecular Biology, Isfahan University of Medical Sciences, Isfahan, Iran

${ }^{2}$ Department of Biology and Anatomical Sciences, Shahid Sadoughi University of Medical Sciences, Yazd, Iran

${ }^{3}$ Department of Reproductive Biology, Research and Clinical Center for Infertility, Shahid Sadoughi University of Medical Sciences,

Yazd, Iran

Corresponding Author: Majid Pourentezari, Department of Biology and Anatomical Sciences, Shahid Sadoughi University of Medical Sciences, Yazd, Iran. Tel: +98-3538203410, Fax: +98-3538203414, Email: m.pourentezari@gmail.com

Received June 25, 2019; Accepted October 25, 2019; Online Published December 5, 2019

\begin{abstract}
Introduction: Avocado and soya unsaponifiables (ASU) have been reported to be useful for the treatment of cartilage diseases. The aim of this study was to detect whether avocado/soybean can have any effect on the chondrogenesis of human adipose-derived stem cells on polylactic-co-glycolic acid/fibrin hybrid scaffold or not.

Materials and Methods: The poly-lactic-co-glycolic acid (PLGA)/fibrin scaffolds were seeded with cultured human adipose tissue-derived stem cells (hADSCs), which were then divided into three groups: control, TGF- $\beta 3$, and ASU and the results were analyzed 14 days later. The viability of the cells in different groups were assessed by MTT. The expression of chondrogenic-related genes Sox9, type /l collagen, Aggrecan, type $X$ collagen, and type I collagen were quantified by real time polymerase chain reaction (PCR). Protein expression levels of collagen type II and X were evaluated by Western blotting.

Results: Enhanced cellular viability was observed in the ASU group compared to the transforming growth factor beta-3 (TGF- $\beta 3$ ) group. Analysis of aggrecan (Agg), type // collagen (Coll2) and SOX9 revealed that ASU and TGF- $\beta 3$ induce hADSCs on PLGA/fibrin scaffold to differentiate into chondrocytes in-vitro. Moreover, a significant decrease was observed in the expression of type X (Coll10) and I collagen (Coll1) genes in the ASU group compared to the TGF- $\beta 3$ group. Protein levels of type // collagen (Coll2) significantly increased in TGF- $\beta 3$ and ASU groups in comparison with those of the control group. However, protein levels of Type X collagen (Coll10) significantly declined in the ASU group when compared with the TGF- $\beta 3$ group.

Conclusions: The results of the present study indicated that hADSCs containing the ASU in PLGA/fibrin hybrid scaffold are an effective way to potentially enhance Cartilage-specific genes with less hypertrophy and Fibrosis in-vitro.

Keywords: Avocado/Soybean, Chondrogenesis, Adipose-Derived Mesenchymal Stem Cells, Scaffold

Citation: Hashemibeni B, Mardani M, Valiani A, Pourentezari M, Anvari M, Yadegari M, Mangoli E. Effects of avocado/soybean on the chondrogenesis of human adipose-derived stem cells cultured on polylactic-co-glycolic acid/fibrin hybrid scaffold. J Appl Biotechnol Rep. 2019;6(4):145-150. doi:10.29252/JABR.06.04.03.
\end{abstract}

\section{Introduction}

There is a growing consensus of interest in the use of botanical material in rheumatoid arthritis and osteoarthritic disorders. Avocado and soybean oils contain a class of biologically active compounds classified as unsaponifiable lipids (avocado/ soybean unsaponifiables [ASUs]). ${ }^{1}$ The main components of ASU, in terms of weight, are the phytosterols beta-sitosterol, stigmasterol and campesterol respectively. Early studies have reflected that the main phytosterols action corresponds to their ability in inhibiting cholesterol absorption and interfering with endogenous cholesterol biosynthesis. ${ }^{2}$ Avocado/ soybean stimulates Coll2 and Agg synthesis while inhibiting stromelysin activity in osteoarthritic chondrocytes. ${ }^{3,4}$ The in-vitro cartilage model usually used to test ASU is based on monitoring the decline of interleukin-1 (IL-1)-induced metalloprotease activity and eicosanoid or nitric oxide synthesis (all agents promoting tissue inflammation and cartilage degradation). ${ }^{5}$

Among a variety of the used scaffolds, the composite scaffold prepared by filling soft hydrogels into hard sponges is highly capable of cartilage regeneration since its advantages can be maintained while avoiding the shortcomings. Irrespective of the higher even distribution of the cells and maintenance of the cell phenotype in hydrogel, bioactive factors, such as growth factors and functional genes, are conveniently loaded into the filled hydrogel with preserved bioactivity. These factors are

Copyright (C) 2019 The Author(s). This is an open-access article distributed under the terms of the Creative Commons Attribution License (http:// creativecommons.org/licenses/by/4.0), which permits unrestricted use, distribution, and reproduction in any medium, provided the original work is properly cited. 
known to regulate the proliferation and differentiation of the seed cells which is particularly important when stem cells are used. ${ }^{6}$

Synthetic scaffold allows a better control of surface morphology, shape and physicochemical and mechanical properties and possesses predictable biodegradation kinetics. Three-dimensional (3-D) poly-lactic-co-glycolic acid (PLGA), which belongs to one of the synthetic scaffolds, has been generally investigated to serve as the substitute for tissue regeneration. It has been approved by the Food and Drug Administration (FDA) of the US for certain clinical applications. However, PLGA fails to present a favorable surface for cell adhesion, proliferation, and differentiation stemmed from the hydrophobic surface and the lack of specific cell-recognizable signals. ${ }^{7}$ To overcome this drawback, an alternative approach addresses the creation of a composite scaffold employing PLGA and a multifunctional biological protein. Because the composite scaffold can be used to create a biomimetic cellular environment by balancing the biofunctional and structural elements, the advent of biosynthetic composite scaffold signifies a major success in tissue engineering. ${ }^{8}$

Fibrin as an excellent natural polymer has attracted a crucial attention in tissue engineering. It presents several important features to the scaffold material such as: 1) it is an FDA approved material and has widely been used in clinical settings due to its high affinity; 2) it possesses hydrophilicity, biocompatibility, and biogradation properties; and 3) it is rich in fibrinogen protein which is a well-characterized extracellular matrix (ECM) molecule with a central role in tissue remodeling and chondrocyte-ECM interaction. ${ }^{9}$

Recently, it was demonstrated that human adipose tissue has mesenchymal stem cells (adipose tissue-derived stem cells, hADSCs) that can be differentiated into multiple cell lineages, including chondrocytes. These cells have great invitro expansion properties and are potentially an alternative cell source for cartilage transplantation. ${ }^{10,11}$ The hADSCs have several advantages over bone marrow stem cells, including easy accessibility and minimal invasiveness.

Although the precise mechanism underlying chondrogenesis in hADSCs is not yet clear, many studies have revealed that growth factors including transforming growth factor- $\beta 3$ (TGF- $\beta 3$ ), insulin like growth factor-1, and fibroblast growth factor can trigger the chondrogenic differentiation of mesenchymal stem cells. ${ }^{11,12}$

Much as ASU has been used in the treatment of osteoarthritis, yet information regarding the effect of invitro use of Avocado/Soybean on chondrogenic induction in hADSCs in PLGA/fibrin scaffold remains to be obtained. The aim of this study was to investigate the impact of ASU on the chondrogenic differentiation of ADSCs in the PLGA/fibrin scaffold.

\section{Materials and Methods}

In order to carry out this study the following tools were purchased from varying facilities: PLGA copolymer (RESOMER ${ }^{\circledR}$ RG 504H, PLGA; 48/52wt\% poly (lactide)/ poly (glycolide) with inherent viscosity of $0.45-0.60 \mathrm{dL} / \mathrm{g}$ $\left(25^{\circ} \mathrm{C} ; 0.1 \%\right.$ in chloroform)) was purchased from Resomer Boehringer Ingelheim, Germany; Hyaluronic acid sodium salt out of Streptococcus equi from Sigma-Aldrich Co.; methylene chloride $(\mathrm{CH} 2 \mathrm{Cl} 2, \mathrm{M}=84.93 \mathrm{~g} / \mathrm{mol})$, triethyl phosphate (TEP: C6H15O4P), calcium nitrate tetra-hydrate $(\mathrm{Ca}(\mathrm{NO} 3) 2.4 \mathrm{H} 2 \mathrm{O})$ and hydrochloric acid $(\mathrm{HCl})$ from Merck Inc.; sodium chloride $(\mathrm{NaCl})$ extra pure salt from Sigma-Aldrich; Cryoprecipitated Antihemophilic Factor (Cryoprecipitated AHF) and fresh frozen plasma (FFP) from the Blood Transfusion Organization of Isfahan, Iran; Calcium gluconate $10 \%$ from the pharmacy; and avocado/soybean from Sigma-Aldrich Co.

\section{Fabrication and Characterization of the Hybrid Scaffold}

As previously described, 3-D PLGA scaffold was prepared via solvent casting and particulate leaching technique using methylene chloride. ${ }^{13}$ Briefly, polymer/solvent solution (8\% w/v PLGA in methylene chloride) was casted in cylindrical silicon molds ( $7 \mathrm{~mm}$ in diameter and $3 \mathrm{~mm}$ in height) which were filled with $\mathrm{NaCl}$ salt particles (particle size of approximately $180 \mu \mathrm{m}$ ) as porogen particle. Then, the scaffolds were dried at room temperature for 12 hours. Finally, to leach out the $\mathrm{NaCl}$ particles, samples were immersed in deionized water for 3 times a day in 2 days to produce highly porous structure.

\section{Fibrin Preparation}

The FFP pocket was placed into bain-marie for 30 minutes at $37^{\circ} \mathrm{C}$. Then, a mixture of FFP $(16 \mathrm{~mL})$ and calcium gluconate $(10 \mathrm{~mL})$ was prepared and casted in a falcon tube so as to be incubated for 90 minutes. After on, the mixture was centrifuged with $2200 \mathrm{rpm}$ for 10 minutes. After centrifugation, the clear supernatant was collected in a falcon tube decanted for thrombin preparation. Fibrinogen was then extracted from cryoprecipitated AHF pocket by heating in bain-marie for 20 minutes at $37^{\circ} \mathrm{C}$. Finally, a mixture which consisted of equal amounts of thrombin and fibrinogen was used to form fibrin clot. $^{13,14}$

Isolation \& Proliferation of ADSCs and Cell Culture on PLGA/ Fibrin Composite Scaffold

The hADSCs were extracted from subcutaneous abdominal adipose tissue harvested from four patients (30-50 years) (Consent had been obtained from the patients in advance.). Adipose tissue was mechanically crushed and rinsed with PBS (Sigma) and was then digested with $0.075 \%$ type I collagenase (Sigma) solution for 30 minutes at $37^{\circ} \mathrm{C}$. Next, Dulbecco's Modified Eagle Medium (DMEM) low glucose medium (Sigma) containing 10\% FBS (Invitrogen) was added for enzyme inactivation before the solution was centrifuged (15 minutes, $1200 \mathrm{rpm}$ ). After removing supernatant, the cell pellet was cultured in $25 \mathrm{~cm}^{2}$ flasks with DMEM low glucose, $1 \%$ penicillin and streptomycin (Gibco), and 10\% FBS and then incubated in $5 \% \mathrm{CO}_{2}, 37^{\circ} \mathrm{C}$. Then, the medium was changed every 4 days. When the cells reached $80 \%$ confluence, they were detached with $0.05 \%$ trypsin $/ 0.53 \mathrm{mM}$ ethylenediaminetetraacetic acid (Sigma) and the cells were seeded at P3 in the scaffolds. ${ }^{10}$ The scaffolds were sterilized 
with $70 \%$ ethanol for 60 minutes, disinfected via ultraviolet light for 2 hours and rinsed with PBS. The sterile scaffold was kept in a 24 well cell culture plate. Finally, the PLGA scaffolds were soaked in hADSCs-fibrinogen suspension $\left(1 \times 10^{6}\right.$ cells/ scaffold) and polymerized by dropping thrombin-calcium chloride $(\mathrm{CaCl} 2)$ solution. ${ }^{15}$

\section{Cell Viability}

The viability of hADSCs in the PLGA/fibrin scaffold among different groups was assessed by the 3-(4, 5-dimethylthiazol2-yl)-2, 5-diphenyltetrazolium bromide (MTT) assay on day 14. First, the medium of each well was removed, washed with PBS, and replaced with $400 \mu \mathrm{L}$ serum free medium and $40 \mu \mathrm{L}$ MTT solution ( $5 \mathrm{mg} / \mathrm{mL}$ in PBS). Second, it was incubated for 4 hours at $37^{\circ} \mathrm{C}, 5 \% \mathrm{CO}_{2}$. The medium was then discarded, $400 \mu \mathrm{L}$ DMSO (Sigma) was added to each well, and the scaffold was incubated in the dark for $2 \mathrm{~h}$. A purple color was created by DMSO after dissolving the formazan crystals. Later, $100 \mu \mathrm{L}$ of the solution was transferred to a 96-well plate and the absorbance of each well was read at $570 \mathrm{~nm}$ with an ELISA reader (Hiperion MPR4). The assays were performed in triplicates. ${ }^{16}$

RNA Isolation and Real-Time Polymerase Chain Reaction Real-Time quantitative RT-PCR was performed to estimate mRNA expression of Coll2, Coll1, Coll10, Agg and SOX9 genes in hADSCs quantitatively among different groups. First, total RNA was isolated by RNeasy mini kit (Qiagen) and treated with RNase-free DNase set (Qiagen) to eliminate genomic DNA. The RNA concentration was determined using a bio photometer (Eppendorf). Second, total RNA (100 ng) was reverse-transcribed to cDNA by RevertAid ${ }^{\mathrm{TM}}$ First Strand cDNA Synthesis kit (Fermentas) according to the manufacturer's instructions. Maxima SYBR Green Rox qPCR master mix kit (Fermentas) was used for real-time RT-PCR (Primer sequences are shown in Table 1. Later, realtime PCR reactions were performed using the comparative $\mathrm{Ct}$ $(\Delta \Delta \mathrm{Ct})$ method. Finally, elative expression level of the genes was computed by calculating the ratio of the amount of the genes to that of the endogenous control (GAPDH). Melting

Table 1. Primers Used in Real Time PCR

\begin{tabular}{|c|c|}
\hline Gene & Primer Sequences (Forward and Reverse) \\
\hline collagen II-F & CTGGTGATGATGGTGAAG \\
\hline collagen II $-R$ & ССTGGATAACCTCTGTGA \\
\hline sox-9-F & TTCAGCAGCCAATAAGTG \\
\hline$S O X-9-R$ & TTCAGCAGCCAATAAGTG \\
\hline collagen $x-F$ & AGAATCCATCTGAGAATATGC \\
\hline collagen $x-R$ & ССТСТТАСТGСТАТАССТTTAC \\
\hline collagen $I-F$ & ССТССAGGGСTCCAACGAG \\
\hline collagen $I-R$ & TCAATCACTGTCTTGCCCCA \\
\hline Aggrecan- $F$ & GTGGGACTGAAGTTCTTG \\
\hline Aggrecan- $R$ & GTTGTCATGGTCTGAAGTT \\
\hline GAPDH-F & AAGCTCATTTCCTGGTATG \\
\hline$G A P D H-R$ & СтTССтСТTGTGСТСТTG \\
\hline
\end{tabular}

curve was produced to determine the melting temperature of specific amplification. These experiments were carried out in triplicate (Table 2). ${ }^{17}$

\section{Western Blot Analysis}

The radio-immune precipitation assay (RIPA) buffer was used to lyse cultured cells to prepare protein extraction. Then, protein samples were electrophoresed at $70 \mathrm{~V}$ for 120 minutes on $7 \%$ SDS polyacrylamide with $5 \%$ stacking gel. The proteins were later transformed with a nitrocellulose paper at $40 \mathrm{~mA}$ for 120 minutes. The nitrocellulose blot was blocked with a solution of $4 \%(\mathrm{~W} / \mathrm{V})$ dry milk for 3 hours. The blot was washed in TTBS and then incubated with collagen type I monoclonal antibody (Abcam) at a 1:1000 dilution overnight. Finally, the goat anti-mouse secondary antibody was added at a dilution of 1:5000 for 3 hours. After final washing, the protein bands were detected with DAB. ${ }^{18}$ The ImageJ method was employed for accurate western blot quantification.

\section{Statistical Analysis}

Kolmogorov-Simonov test was used for assessing the normal distribution of variables. Moreover, (one-way-analysis of variance) (ANOVA) with LSD post hoc test were applied for the comparison of MTT, real-time PCR, and western blot results in different groups.

\section{Results}

MTT Results

The MTT results on the fourteenth day showed a higher viability in the ASU affected group compared to the TGF- $\beta 3$ group; the difference, however, was not significant $(P>0.05)$ (Figure 1).

Real-Time Polymerase Chain Reaction The results of the real-time PCR represented that SOX9, Coll2 and $A g g$ gene expression in the TGF- $\beta 3$ and ASU groups stand

Table 2. Time and Temperature of the Real-Time PCR Cycles

\begin{tabular}{lc}
\hline Steps & Temperature and Time \\
\hline Initial denaturation & $95^{\circ} \mathrm{C}$ for $10 \mathrm{~min}$ \\
Cycle denaturation & $95^{\circ} \mathrm{C}$ for $15 \mathrm{~s}$ \\
Annealing \& extension & $60^{\circ} \mathrm{C}$ for $1 \mathrm{~min}$ \\
\hline
\end{tabular}

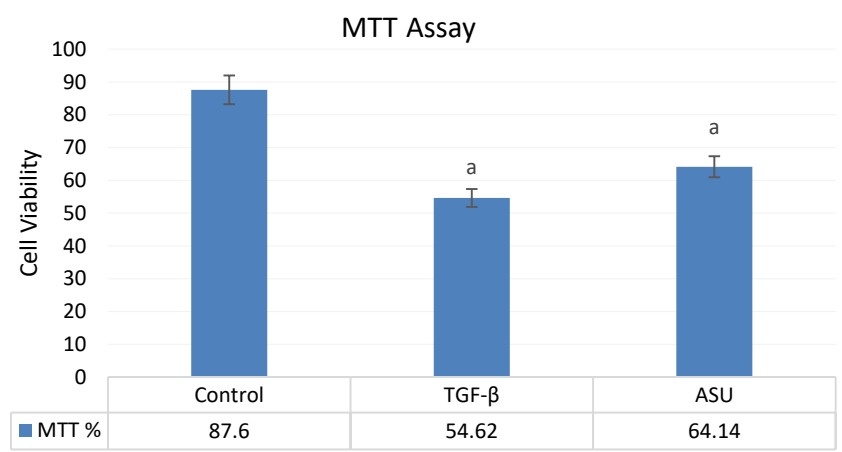

Figure 1. Comparison of MTT Assay Results Between ASU and TGF- $\beta 3$ Groups. a Significant compared to control group $(P \leq 0.05)$. 
significantly higher $(P<0.05)$ than those in the control group. In addition, the results of the real-time PCR indicated that Coll10 (as hypertrophic marker) and Coll1 (as fibrous marker) gene expression in the group affected by ASU is lower than that in the TGF- $\beta 3$ and control groups $(P<0.05)$ (Figure 2$)$.

\section{Western Blot Analysis}

The results of the western blot revealed a significantly higher level of Coll 2 protein in the TGF- $\beta 3$ and ASU groups compared to the control group $(P<0.05)$. Additionally, the results of the western blot indicated that the Coll10 protein in the group affected by ASU turns to be lower than the TGF- $\beta 3$ and control groups (Figure 3).

\section{Discussion}

Tissue engineering widely relies on the use of $3 \mathrm{D}$ porous scaffolds to present an appropriate environment for the renewal of tissues and organs. These scaffolds fundamentally act as a template for tissue formation and are usually seeded with cells or occasionally with growth factors. ${ }^{19}$ A welldesigned 3D scaffold is an important factor to guide tissue formation in-vitro and in-vivo. Numerous attempts have been made for tissue reconstruction using the PLGA based studies. A number of methods, such as gas forming, freeze-drying or salt leaching have been reported to produce $3 \mathrm{D}$ porous matrices from natural and synthetic polymers. In the present study, the solvent casting and particulate leaching system was successfully used to fabricate the PLGA scaffold. ${ }^{13}$

A PLGA scaffold fabricated on a SC/PL system is not much appropriate for cell attachment, which in turn affects cell proliferation and differentiation. So a hybrid scaffold is required to solve the problem. Therefore, an effort was made to overcome this problem by using fibrin in combination with PLGA. ${ }^{9}$

Growth factors play a crucial role in the regulation of adult stem cells differentiation. A number of studies have demonstrated the potential of bone morphogenetic protein, insulin-like growth factor and TGF- $\beta 3$ in inducing chondrogenic differentiation in-vitro and promoting the formation of cartilage-like tissue in-vivo. ${ }^{6,20,21}$ However, some growth factors such as TGF- $\beta 3$ not only upregulate the expression of hyaline cartilage specific markers, but unavoidably lead to further hypertrophic differentiation and contribute to the development of fibrous cartilage.22-24 Furthermore, rapid degradation, easily lost activity, and the high cost of growth factors limit their widespread use, particularly in clinical practices. ${ }^{25-27}$

The ASUs are natural vegetable extracts made up of avocado and soybean oils in a proportion of one-third to two-thirds. ${ }^{28}$ In a study, Gabay et al reported that avocado/soybean reduce the activity of the transcription factor nuclear factor- $\mathrm{\kappa B}$ in an inflammatory model induced by tumor necrosis factor- $\alpha$ and protect chondrocytes from damage due to osteoarthritis. ${ }^{29}$ Previous studies have revealed that ASU significantly affects

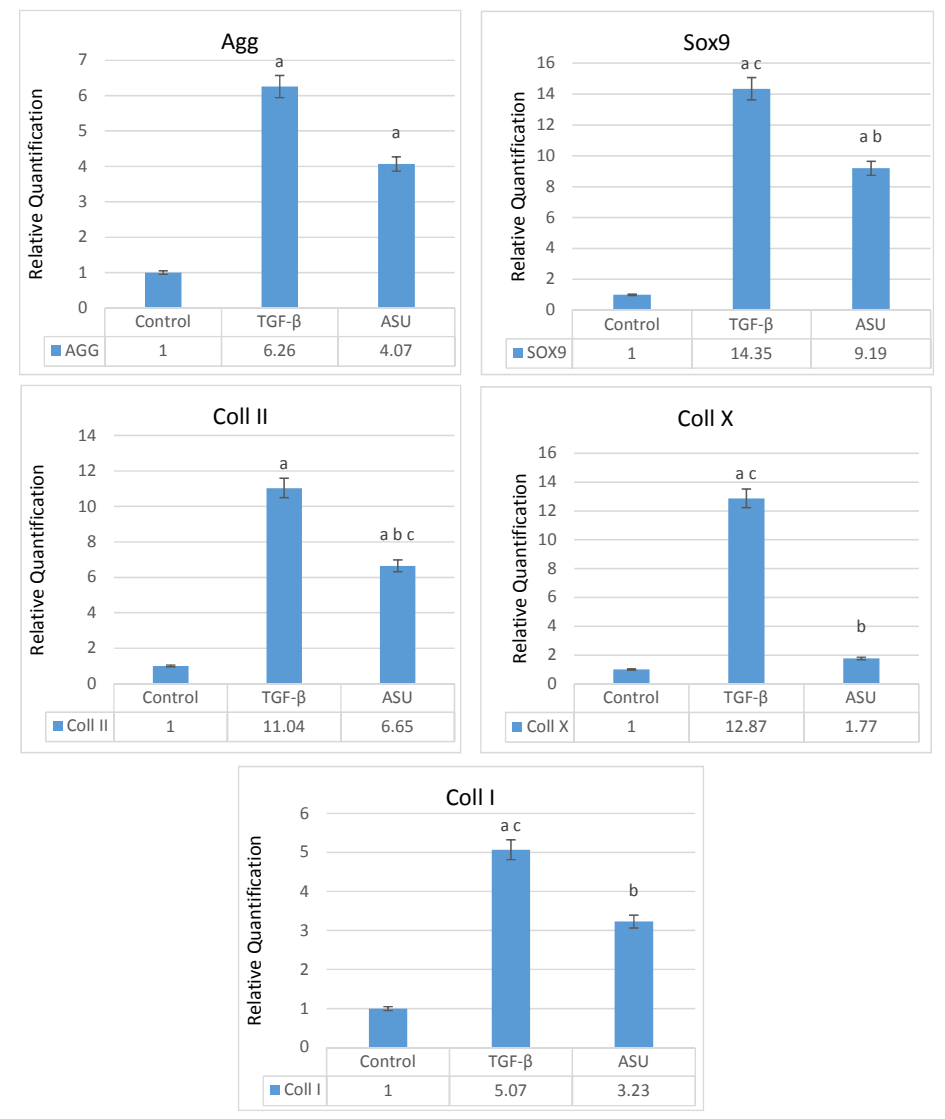

Figure 2. Quantitative Expression Status of the Agg, Sox 9, Coll2, Coll10 and Coll1 Genes Analyzed by Real-Time PCR.

a Significant compared to control group; ${ }^{\text {b }}$ Significant compared to ASU group $(P \leq 0.05)$. 


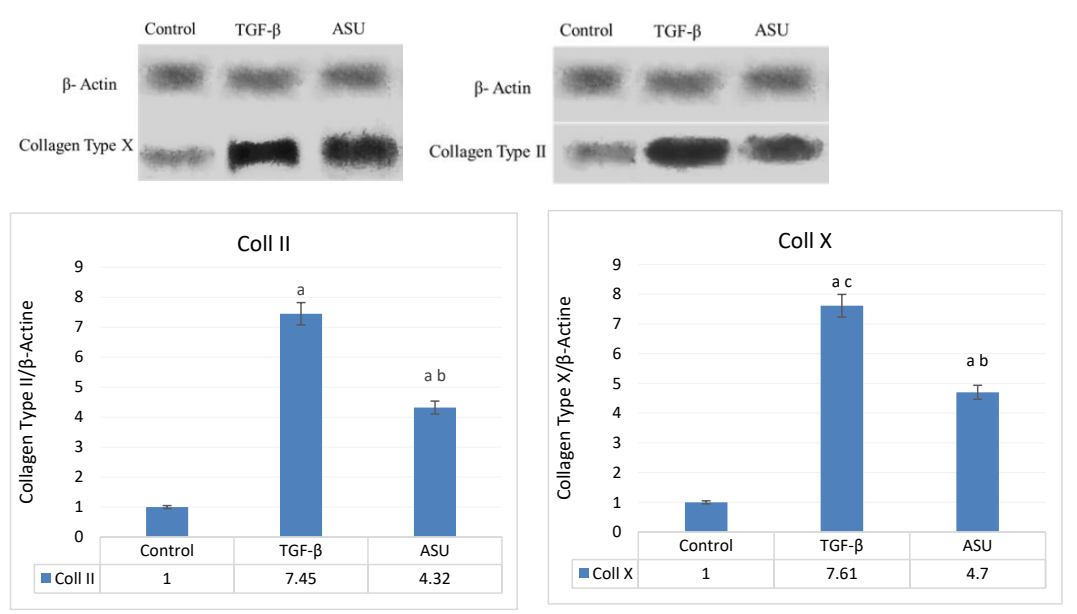

Figure 3. Expression of Coll2 and Coll10 Proteins After 14 days of Induction Examined by Western Blot. $\beta$-Actin was used as an internal control. a Significant compared to control group; ${ }^{\text {b }}$ Significant compared to ASU group $(P \leq 0.05)$.

the expression levels of cartilage specific genes Coll2, Agg and SOX9. Similarly, as shown in this study, ASU upregulates the expression levels of these genes significantly.

It has been shown that a number of mechanisms can influence chondrocyte metabolism. For example, ASU enhances the synthesis of TGF- $\beta 3^{30}$ and inhibits metalloprotease activity and eicosanoid synthesis. ${ }^{31}$ In addition, sterols are quickly incorporated into the cells and enhance cellular antioxidant status. ${ }^{32}$ In regards to cell viability, the results of the present study are also in agreement with those of Basiri et al's study. As they maintain, the treatment with ASU promotes the viability and proliferation of the ADSCs compared to the treatment with TGF- $\beta 3 .{ }^{33}$ In the present study, it was observed that TGF- $\beta 3$ alone leads to a higher collagen $x$ expression. However, the presence of ASU does not potentiate the effect of the growth factors on hypertrophic differentiation while producing chondrogenic differentiating effects. Similarly, other studies identified that ASU down regulates collagen $\mathrm{x}$ gene expression. ${ }^{34}$ Furthermore, Blaine et al demonstrated that ASU significantly affects the expression levels of cartilage-specific genes and leads to higher levels of Agg and Coll 2 production. ${ }^{28}$ It was similarly observed in the present study that ASU notably upregulates the expression levels of these genes, increases the staining intensity and protein levels of Coll2 while reducing Coll10 protein.

\section{Conclusions}

Using ASU can induce chondrogenesis in hADSCs in PLGA/ fibrin composite scaffold. This can be deduced with the increase of special markers of hyaline cartilage and reduction of hypertrophic and fibrosis markers in comparison with the growth factor TGF- $\beta 3$. In general, this nature compound is suitable for the inducing factors of chondrogenesis.

\section{Authors' Contributions}

Conceptualization: BH, MP. Data curation: MM. Formal analysis: EM. Methodology: MA, EM, MP. Writing - original draft: MY. Writing review \& editing: AV, MP.

\section{Conflict of Interest Disclosures}

The authors declare they have no conflicts of interest.

\section{Acknowledgments}

The authors would like to thank the Research Deputy which is affiliated to the Isfahan University of Medical Sciences, Iran for all their financial support.

\section{References}

1. Cornblatt BS. Letter to the Editor for "Management of Osteoarthritis with Avocado/Soybean Unsaponifiables". Cartilage. 2016;7(1):112113. doi:10.1177/1947603515623153.

2. Ling WH, Jones PJ. Dietary phytosterols: a review of metabolism, benefits and side effects. Life Sci. 1995;57(3):195-206. doi:10.1016/0024-3205(95)00263-6.

3. Kut-Lasserre C, Miller CC, Ejeil AL, et al. Effect of avocado and soybean unsaponifiables on gelatinase A (MMP-2), stromelysin 1 (MMP-3), and tissue inhibitors of matrix metalloproteinase (TIMP- 1 and TIMP-2) secretion by human fibroblasts in culture. J Periodontol. 2001;72(12):1685-1694. doi:10.1902/ jop.2001.72.12.1685.

4. Henrotin YE, Deberg MA, Crielaard JM, Piccardi N, Msika $\mathrm{P}$, Sanchez C. Avocado/soybean unsaponifiables prevent the inhibitory effect of osteoarthritic subchondral osteoblasts on aggrecan and type II collagen synthesis by chondrocytes. J Rheumatol. 2006;33(8):1668-1678.

5. Henrotin YE, Sanchez C, Deberg MA, et al. Avocado/soybean unsaponifiables increase aggrecan synthesis and reduce catabolic and proinflammatory mediator production by human osteoarthritic chondrocytes. J Rheumatol. 2003;30(8):1825-1834.

6. Wang W, Li B, Yang J, et al. The restoration of full-thickness cartilage defects with BMSCs and TGF-beta 1 loaded PLGA/fibrin gel constructs. Biomaterials. 2010;31(34):8964-8973. doi:10.1016/j. biomaterials.2010.08.018.

7. Pang L, Hu Y, Yan Y, et al. Surface modification of PLGA/ $\beta$-TCP scaffold for bone tissue engineering: hybridization with collagen and apatite. Surf Coat Technol. 2007;201(24):9549-9557. doi:10.1016/j.surfcoat.2007.04.035.

8. Dikovsky D, Bianco-Peled H, Seliktar D. The effect of structural alterations of PEG-fibrinogen hydrogel scaffolds on 3-D cellular morphology and cellular migration. Biomaterials. 2006;27(8):1496-1506. doi:10.1016/j.biomaterials.2005.09.038.

9. Wei Y, Hu H, Wang H, Wu Y, Deng L, Qi J. Cartilage regeneration of adipose-derived stem cells in a hybrid scaffold from fibrin-modified PLGA. Cell Transplant. 2009;18(2):159-170. doi:10.3727/096368909788341261.

10. Valiani A, Hashemibeni B, Esfandiary E, Ansar MM, Kazemi M, Esmaeili N. Study of carbon nano-tubes effects on the chondrogenesis of human adipose derived stem cells in alginate scaffold. Int J Prev Med. 2014;5(7):825-834. 
11. Zuk PA, Zhu M, Mizuno H, et al. Multilineage cells from human adipose tissue: implications for cell-based therapies. Tissue Eng. 2001;7(2):211-228. doi:10.1089/107632701300062859.

12. Wang $L$, Ren $M M$, Jian $Y L$, et al. [Experimental studies on the repair and restitution of cartilage by cartilage acellular extracellular matrix and adipose tissue-derived stem cells]. Zhonghua Er Bi Yan Hou Tou Jing Wai Ke Za Zhi. 2019;54(2):133-138. doi:10.3760/ cma.j.issn.1673-0860.2019.02.007.

13. Tavakoli E, Mehdikhani-Nahrkhalaji M, Hashemi-Beni B, ZargarKharazi A, Kharaziha M. Preparation, characterization and mechanical assessment of poly (lactide-co-glycolide)/hyaluronic acid/fibrin/bioactive glass nano-composite scaffolds for cartilage tissue engineering applications. Procedia Materials Science. 2015;11:124-130. doi:10.1016/j.mspro.2015.11.126.

14. Yang SH, Wu CC, Shih TT, Chen PQ, Lin FH. Three-dimensional culture of human nucleus pulposus cells in fibrin clot: comparisons on cellular proliferation and matrix synthesis with cells in alginate. Artif Organs. 2008;32(1):70-73. doi:10.1111/j.15251594.2007.00458.x.

15. Sha'ban M, Kim SH, Idrus RB, Khang G. Fibrin and poly (lacticco-glycolic acid) hybrid scaffold promotes early chondrogenesis of articular chondrocytes: an in vitro study. J Orthop Surg Res. 2008;3:17. doi:10.1186/1749-799x-3-17.

16. Ansar MM, Esfandiariy E, Mardani M, et al. A comparative study of aggrecan synthesis between natural articular chondrocytes and differentiated chondrocytes from adipose derived stem cells in 3D culture. Adv Biomed Res. 2012;1:24. doi:10.4103/22779175.98145

17. Esfandiari E, Roshankhah S, Mardani M, et al. The effect of high frequency electric field on enhancement of chondrogenesis in human adipose-derived stem cells. Iran J Basic Med Sci. 2014;17(8):571-576. doi:10.22038/ijbms.2014.3188.

18. Hashemibeni B, Jafary F, Esmaeil N, et al. Comparison of phenotypic characterization between differentiated osteoblasts from stem cells and calvaria osteoblasts in vitro. Int J Prev Med. 2013;4(2):180-186.

19. O'Brien FJ. Biomaterials \& scaffolds for tissue engineering. Mater Today. 2011;14(3):88-95. doi:10.1016/S1369-7021(11)70058-X.

20. Kolambkar YM, Peister A, Soker S, Atala A, Guldberg RE. Chondrogenic differentiation of amniotic fluid-derived stem cells. J Mol Histol. 2007;38(5):405-413. doi:10.1007/s10735-0079118-1.

21. Jung MR, Shim IK, Chung HJ, et al. Local BMP-7 release from a PLGA scaffolding-matrix for the repair of osteochondral defects in rabbits. J Control Release. 2012;162(3):485-491. doi:10.1016/j. jconrel.2012.07.040.

22. Giovannini S, Diaz-Romero J, Aigner T, Heini $P$, Mainil-Varlet $P$, Nesic D. Micromass co-culture of human articular chondrocytes and human bone marrow mesenchymal stem cells to investigate stable neocartilage tissue formation in vitro. Eur Cell Mater. 2010;20:245-259. doi:10.22203/ecm.v020a20.

23. Aung A, Gupta G, Majid G, Varghese S. Osteoarthritic chondrocytesecreted morphogens induce chondrogenic differentiation of human mesenchymal stem cells. Arthritis Rheum. 2011;63(1):148158. doi:10.1002/art.30086.

24. Mueller MB, Fischer M, Zellner J, et al. Effect of parathyroid hormone-related protein in an in vitro hypertrophy model for mesenchymal stem cell chondrogenesis. Int Orthop. 2013;37(5):945-951. doi:10.1007/s00264-013-1800-1.

25. Zhang L, Zhang X, Li KF, et al. Icariin promotes extracellular matrix synthesis and gene expression of chondrocytes in vitro. Phytother Res. 2012;26(9):1385-1392. doi:10.1002/ptr.3733.

26. Li D, Yuan $T$, Zhang $X$, et al. Icariin: a potential promoting compound for cartilage tissue engineering. Osteoarthritis Cartilage. 2012;20(12):1647-1656. doi:10.1016/j.joca.2012.08.009.

27. Fan JJ, Cao LG, Wu T, et al. The dose-effect of icariin on the proliferation and osteogenic differentiation of human bone mesenchymal stem cells. Molecules. 2011;16(12):10123-10133. doi:10.3390/molecules161210123.

28. Christiansen BA, Bhatti S, Goudarzi R, Emami S. Management of osteoarthritis with avocado/soybean unsaponifiables. Cartilage. 2015;6(1):30-44. doi:10.1177/1947603514554992.

29. Gabay O, Gosset M, Levy A, et al. Stress-induced signaling pathways in hyalin chondrocytes: inhibition by Avocado-Soybean Unsaponifiables (ASU). Osteoarthritis Cartilage. 2008;16(3):373384. doi:10.1016/j.joca.2007.06.016.

30. Altinel L, Sahin O, Köse KC, et al. [Healing of osteochondral defects in canine knee with avocado/soybean unsaponifiables: a morphometric comparative analysis]. Eklem Hastalik Cerrahisi. 2011;22(1):48-53.

31. Henrotin YE, Labasse AH, Jaspar JM, et al. Effects of three avocado/ soybean unsaponifiable mixtures on metalloproteinases, cytokines and prostaglandin E2 production by human articular chondrocytes. Clin Rheumatol. 1998;17(1):31-39. doi:10.1007/bf01450955.

32. Vivancos $M$, Moreno JJ. beta-Sitosterol modulates antioxidant enzyme response in RAW 264.7 macrophages. Free Radic Biol Med. 2005;39(1):91-97. doi:10.1016/j.freeradbiomed.2005.02.025.

33. Basiri A, Hashemibeni B, Mardani M, Esfandiari E. Ps-19: The Effect of Avocado/Soybean Unsaponifiables (Piascledine) on Viability of Human Articular Chondrocytes and Adipose Derived Stem Cells. Cell J (Yakhteh). 2014;16(Suppl 1).

34. Ownby SL, Fortuno LV, Au AY, Grzanna MW, Rashmir-Raven AM, Frondoza CG. Expression of pro-inflammatory mediators is inhibited by an avocado/soybean unsaponifiables and epigallocatechin gallate combination. J Inflamm (Lond). 2014;11(1):8. doi:10.1186/1476-9255-11-8. 